\title{
Maternal and child nutrition in rural Chhattisgarh: The role of health beliefs and practices
}

From research in central Chhattisgarh, this paper interprets the bearing that healthcare beliefs and practices may have in shaping maternal and child nutrition both in light of biomedical recommendations and within the context and constraints of a rural village setting. It contends that health beliefs and practices that are at variance from biomedical recommendations appear to have few consequences for gestational nutrition and for child health in relation to pregnancy. In the postpartum however, health ideas at variance from biomedical recommendations appear to have an important bearing on maternal nutrition and infant feeding, and may put mothers and children at risk of nutritional deficiency. Maternal 'eating down' following a surgical procedure such as a caesarean delivery or tubectomy is especially noteworthy, since food intake quantity is reduced over an extended time frame. While caring practices are influenced by cultural formulations, they also reflect, perhaps, adaptations to health risks.

Keywords: Culture, reproduction, nutrition, infant feeding, poverty, health beliefs, India, Chhattisgarh 


\section{Introduction}

Although UNICEF's multi-layered conceptual framework on the biomedical and socio-economic roots of undernutrition (UNICEF 2013) is widely accepted by the nutrition scientific community, there remain divergent standpoints on what the key drivers of undernutrition are. By one influential position, the lack of 'knowledge' of biomedical recommendations is perceived to act as an important barrier to good nutrition. Consider the statement by Robert Black, leader of the Lancet Maternal and Child Undernutrition Study Group in an interview to Boseley (2008), "It is not really a poverty issue. It really is that the quality of the diet and quality of the complementary foods given to babies at that age are not adequate. It is possible within a local context to get those foods. It is just lack of knowledge”. In public health practice, the term 'knowledge' continues to be understood to mean a 'scientific fact' or biomedical 'truth', and is viewed in contrastive terms to the idea of 'beliefs', which are assumed to be synonymous with untruths ${ }^{i}$. While Black was speaking for the global context of child nutrition, the stance that erroneous healthcare ideas and practices are of disproportionate importance for maternal and child nutrition continues to be widely echoed in India. Representatives of civil society organisations, bureaucrats and members of bilateral institutions such as UNICEF, commonly view not poverty, but inappropriate health beliefs and practices as key obstacles to good nutrition. They consequently display frustration over what is, in their view, public programme preoccupation with 'food dole' over health and nutrition education ${ }^{\mathrm{ii}}$.

The juxtaposition of 'knowledge' and 'beliefs' as contrastive terms is, however, widely critiqued by medical anthropologists. Taking a position within the interpretive tradition and in line with critical theory, they highlight, for instance, the limits of the language of beliefs and behaviour adopted by medical behavioural sciences, and argue the importance of the wider political economy determining human decisionmaking and behaviour (Singer 1989; Good 1993; Lock and Scheper-Hughes 1990). Furthermore, as Pelto and Pelto contend, biomedical health professionals, and rural village communities alike have systems of beliefs that shape health understanding, albeit beliefs that may be based on different criteria or evidence (1997, 148-49). Moreover, biomedical positions are continually modified in light of new information, and hence, what may be understood as a scientific fact or truth is historically 
contingent. Taking breastfeeding as an example, there is broad based scientific consensus on the value of breast milk as the best source of infant nourishment (WHO 2002), with positive links to child survival (Huffman, Zehner, and Victora 2001). The World Health Organisation (WHO) recommends exclusive breastfeeding for the first six months of life, following which it recommends the introduction of complementary foods. It is noteworthy however, that WHO recommendations on exclusive breastfeeding have changed as recently as 2001 when it was recommended for the first six months after birth over the previous four-six months ${ }^{\mathrm{iii}}$. Furthermore, the six month timeframe remains debated and is argued as excessive in the context of developed countries (Kramer and Kakuma 2012; Reilly and Wells 2005; Fewtrell et al. 2011). On the related subject of complementary feeding, WHO (2003) guidelines on feeding behaviours, form and food quantities, are now challenged by research on baby-led weaning, which advocates that babies play a greater role in regulating food intake; that they self-feed family foods from the outset and that they be offered solid foods rather than purees (Rapley 2016; Wright et al. 2011; Townsend and Pitchford 2012). Similarly, nutrition science on micronutrient supplementation remains contested.

A historicised perspective reveals then problems with assumptions that biomedical knowledge is a 'truth' against which cultural health or nutrition beliefs may be measured. While these limits and nutrition debates are recognised, biomedicine continues to underpin the widely accepted international benchmarks for public health and nutrition. Within this background, the analytical intentions of the paper are to communicate ethnographic observations on health and nutrition ideas and practice in light of current biomedical recommendations, while also interpreting them in the context of local worlds and socio-economic realities of a Chhattisgarhi village. Although the research did not have strictly 'applied' or action-oriented objectives, the larger study of which it is part sought to uncover drivers of reproductive health and child nutrition from both a scholarly and public health viewpoint ${ }^{\mathrm{iv}}$. While the paper describes and interprets health behaviours from an anthropological perspective, it does not intend to establish causality in biomedical terms. 


\section{Ethnographic setting and methods}

The empirical material is gathered over 12 months of research undertaken between 2011 and 2013 in a village the author calls Nariar from the fertile rice-growing plains of Chhattisgarh $^{\mathrm{v}}$. Located 25 kilometres from the state capital Raipur the village has, by the 2011 census, a population of 1042. In Nariar, the Sahu (oil-presser) and Yadav (cattle-herder) castes have 6 households each, 60 households are of the Satnami (a sect within the Hindu fold, former untouchable castes now listed as Scheduled Castes) and approximately 40 households belong to the Pardhi (a 'de-notified' tribe previously classified by colonial administrators as 'criminal') 'vi The Sahu, Yadav and Satnami have a prominent regional presence, although the Pardhi, a small tribe, have a unique presence in Nariar. There are no households of upper castes. Farming and informal employment forms the economic mainstay for most communities in the region. The Pardhi however have a nomadic history of fowling and foraging. Although some households now own farmlands, broom or mat making is the primary occupation while fowling endures as fundamental to their shikari (hunter) or chidimar (bird-hunter) identity. All communities and most households consume meat, although some households or individuals are vegetarian from religious motivation.

The data was generated primarily from ethnographic observation and interview involving a range of stakeholders in the village and outside it, especially families of pregnant women and mothers of young children. Social settings such as the monthly antenatal clinic at the aanganwadi or child development centre and street side community gatherings were sites for data generation. Data was further sourced from in-depth engagement with members of 23 households across the Sahu, Yadav, Satnami and the Pardhi. The research followed usual ethnographic fieldwork procedures. Research engagements were ongoing rather than one-off, and involved iterative movements between data generation, analysis and interpretation. Households sampled for in-depth engagement were selected and built as the research progressed, and data was generated over multiple contacts with informants across social settings over a period of one year, and in some cases longer, as initial contact with some informants was made about 12 months prior to the main phase of fieldwork ${ }^{\text {vii }}$. Sample households included members who were young children, or women who were pregnant or lactating. The sample attempted to include class diversity from criteria 
such as occupation of household members and from observed material standard of living. Multiple nuclear families commonly shared a joint dwelling, facilitating wider engagement within a household setting. Ethical approval for the study was obtained from .... The study purpose and identity of the researcher were upfront and oral consent to participation was obtained. Names of individuals, entities and some places are altered in the text with a view to protect identity.

\section{Diet in pregnancy}

Pregnancy is often accompanied by dietary modifications observed with a view to maintain wellbeing of a pregnant woman and her unborn child (Ferro-Luzzi 1980; Van Hollen 2003; Placek and Hagen 2015). From a bio-medical perspective, literature indicates that cultural ideas may have a negative influence on maternal nutrition in India (Nag 1994). Additionally, there is the concern that women in developing countries may not increase their food intake or may even deliberately reduce intake, or 'eat-down', from fear of the perceived positive relationship between food intake, foetal-size, and risks for obstructed labour (Brems and Berg 1988). A review of studies from India found that pregnant women commonly eat-down in pregnancy and avoid valued nutritious and animal foods classified as 'hot', which have a positive relationship with foetal growth (Nag 1994, 2437) ${ }^{\text {viii }}$.

\section{Beliefs and practices related to diet in pregnancy}

In my case, in the heat, I desired 'cold foods' during pregnancy and therefore ate cold foods in particular - seeking out curd, cold fruits and milk apart from khana (the staple food, rice). I did not eat 'hot foods'. For individuals to whom both hot and cold foods suit, they should eat them both. A person should eat by the directive of what suits them.

...Tuma and Kochai (root vegetables) are not eaten. Phuttu (mushrooms) are also not eaten as eating this may lead to the child having scars at birth, and on eating too much chilli the child may be born without hair...

[Rekha, reflecting on when she was pregnant with Amit, Satnami]

When the child is in the womb one can eat everything, cold foods, hot foods, everything.

[Renuka, Rekha's saas (mother-in-law), Satnami] 
The statements of Rekha, and her saas summarise observed practice on gestational dietary intake. The emphasis, across communities, is on the pregnant woman's own regulation of diet based on her inclinations, considerations of food-palatability, and judgement of individual bodily constitution. Pregnant women in Nariar make few if any dietary modifications and any alterations usually reflect personal considerations of food palatability relating to nausea in pregnancy. While Rekha states particular foods that may be avoided, overall, these are uncommonly and inconsistently recollected, are not part of everyday diet, and do not expressly include high value, nutrient rich, or animal foods. Importantly, food rules do not proscribe the range of foods classified as hot or cold by humeral criteria but instead relate to 'particular' foods shunned for their perceived influence on appearance of the child (food classification by hot and cold criteria influences a larger food-range, and I come to this discussion later with reference to postpartum and infant nutrition). Rekha's statement on preference of cold foods during pregnancy reflects her adjustments to perceived bodily composition and possibly to climate by humeral criteria ${ }^{\mathrm{ix}}$. However, most women in Nariar do not report any consistent dietary adjustments during pregnancy by humeral criteria. It is occasionally voiced that foods classified, as having thanda or cooling properties should be avoided in late pregnancy to safeguard the advanced foetus from catching the dreaded sardi or 'common cold'. In practice however, mirroring the conclusions of Jeffery, Jeffery, and Lyon $(1989,78)$, pregnant women report few if any diet modifications.

Furthermore, women report eating 'pet-bhar' or 'to a full stomach' while pregnant in contrast to their deliberate practice of 'kum kum khana' or 'eating to less than a full stomach' in the postpartum (I come to this discussion later). One woman indicated that in years past, community elders might admonish pregnant women for eating too much, from fear of 'cramping the baby in the womb'. This conception perceived the growing foetus as sharing the same physical space as food, and viewed 'excessive' food as impinging on foetal space, an idea also articulated in other parts of India (Nichter 1983; Jeffery et al. 1989,78; Nag 1994). However the relation between dietary intake and 'baby space' remained an inconsistent and dated notion, an isolated statement only recalled on probing. From both observation and testimony, this idea had negligible influence on food intake 'quantity' in living memory ${ }^{\mathrm{x}}$. Food 'proscriptions' during pregnancy are then insignificant and women make few if any 
dietary changes. Moreover, women recognise that a 'small baby' at birth signalled health vulnerabilities ${ }^{\mathrm{xi}}$. Notwithstanding the desire for healthy babies however, the fear of babies growing 'too large' as alluded to by Brems and Berg (1988) is real. It is noteworthy that 'food intake' is not associated with a 'too-large' birth size, and women report 'eating to their fill'. However, while food is viewed as natural with a non-linear relation to baby size, 'micronutrient pills' are feared as being synthetic, with the potential to create a more direct and artificial increase in foetal size as illustrated by the following case discussion.

\section{Kalpana's pregnancy}

Kalpana came into Nariar in marriage to Harish, and was, in October 2011, about 7 months pregnant with her first child. The family were Satnami, and Kalpana, among the few women graduates in Nariar had recently acquired the much-sought job of aanganwadi worker at the second village aanganwadi.

Through pregnancy Kalpana carried on with regular activity, and assumed an indifferent attitude to care - 'you know all of this immunisation, eating well and so on'. She planned to follow through on immunisation, but did not intend on making dietary modifications or monitoring weight gain. The packets of supplementary nutrition provided by the aanganwadi for pregnant women (wheat, lentils, jaggery and oil ground together) which she was responsible for distributing and recognised the nutrient worth of, had no place in her diet and were summarily dismissed - 'I don't eat all of that, we eat what we eat'.

Kalpana did not view her aanganwadi work as particularly demanding 'Where do I work that I will feel hungry? What real work is there at an aanganwadi centre? Mainly sitting around kids is it not?'. Her main activities at the centre were record management and supervision. Unlike most village women, Kalpana did not labour on the farm. She had a non-manual, secure job, and moreover, unlike many women, did not have to bring water or firewood.

Although registered with a local private maternity hospital 'Priya Multi' for antenatal care, a trend amongst Nariar's more prosperous households, Kalpana displayed no definite preference for 'home' or 'hospital' as a birthing venue. Kalpana had one lingering concern however. Into the third trimester, she could not feel foetal movements or as she put it, 'the baby playing'. Following advice of the Auxiliary Nurse Midwife (ANM), Kalpana visited, along with Harish, the government medical camp at the Primary Health Centre for a wide-ranging examination. She also travelled to Raipur to consult an additional private doctor and for a sonography. Various service providers advised that all was normal. Kalpana was fearful of the multivitamin pills she had been prescribed though, and skipped most doses, worried that they would lead the foetus to grow 'too large' in the womb and make for difficult birthing. 
In an environment where home births were preferred and predominant ${ }^{\mathrm{xii}}$, obstetric care limited and hospital-based deliveries beheld by many with dread, Kalpana's avoidance or discontinuance of multivitamin pills is from fear of a 'too-large' baby making for prolonged, difficult or obstructed labour. Biomedical service providers, such as the Auxiliary Nurse Midwife, Tarni, shared the notion that gestational consumption of micronutrient pills could create a perceptible increase in birth size. As Tarni scanned the filed multi-vitamin prescriptions from a pregnancy managed at 'Priya Multi', she remarked, for instance, 'private service providers prescribe antenatal micronutrient pills to "fatten the baby up" in-utero to then "do the scissor"'. This implied that private doctors work in their self-interest to make normal birthing difficult, forcing thereby, the significantly more expensive caesarean section.

In the context of rural Chhattisgarh where micronutrient deficiencies are widespread, vitamin pill avoidance may have implications for foetal development and maternal nutrition, although from the perspective of biomedicine, there is noteworthy lack of clarity on benefits of antenatal supplementation (apart from the wide consensus regarding folic acid and iron supplementation) ${ }^{x i i i}$. However, while cultural rules allow diets 'to a full stomach', households make few positive concessions for gestational nutrition in resource allocation. Women rarely leveraged pregnancy to facilitate diet modifications to allow higher value foods, and there were few attempts to provide for diet improvements or increased food-intake that biomedicine recommends for the third trimester. Gender relations in the region of Nariar are egalitarian in relation to much of India, and observation indicates no perceptible gender discrimination in intra-household food distribution ${ }^{\text {xiv }}$. The scarce availability of higher value or nutrient rich foods, and common large family-size, with other children therein, lead women and families to refrain from making disproportionate nutrient allocations for pregnant women. As noted, any disproportionate food allocation or selective consumption was usually because of matters of food palatability and nausea, and from within already available foods.

In the region of Nariar, rice is the primary staple and quality diets are constrained by income. For most households, the two main meals of the day consist of rice, and one other main accompaniment, either ' $d a l$ ' (lentils) or 'sabji' (a vegetable preparation) but rarely both. Milk, meat, eggs and fruit are particularly rationed. Depending on 
economic status, households may consume eggs in 1-2 days per week (usually 1 egg per person). Meat may be a weekend or fortnightly treat. While treats such as a savoury snack, ice-lollies and biscuits, are not uncommon, individual shares are small. Only a handful of households consume milk and these commonly had a milking cow or are relatively wealthy. Here too, the consumption of milk or its products in individual portions is not the practice and milk is mainly an additive in tea (large households of 20 members may consume about $1 / 2$ litre of milk in a day).

Although financial constraints to nutritious diets remain important barriers, observations highlight the scope to better prioritise resources for gestational nutrition. Notwithstanding Kalpana's registration for private antenatal care and her seeking a range of biomedical advice at significant financial expense, she summarily rejects nutrition advice. Kalpana does not change diet quality and rejects aanganwadi nutrient supplements. While for Kalpana's family both dal and sabji are available regularly, finances place constraints on consumption of animal-source proteins such as meat or milk. Meat or fish is a weekly treat, and milk is not consumed everyday but only on occasion. It could be argued however that in Kalpana's case, and for some other households, finances could be mobilised for better gestational nutrition.

\section{Postpartum and Infant Nutrition in Nariar}

All communities initiate breastfeeding soon after birth and, notwithstanding the failure of lactation, a child is breastfed exclusively for the first six months of life, and ordinarily, as discussed below, exclusively well beyond this time. This early initiation of breastfeeding is a longstanding custom and the practice of feeding pre-lacteals or of discarding the protein-rich colostrum, common in many parts of India, is absent ${ }^{\mathrm{xv}}$. During this phase, postpartum maternal diet is significantly adapted with a view to protect the mother-child dyad from the cold, heat loss and illness ${ }^{\mathrm{xvi}}$. Furthermore, it is adapted with a view to heal internal wounds that the birthing process is understood to inflict on the mother, and to safeguard the breastfed infant from the threats of cold, cough, fever and indigestion. While most exacting in the first week, dietary modifications are typically observed for one-year postpartum. 


\section{Postpartum maternal diet: 'to eat or not to eat'?}

After the baby is born everything is restricted ( $s a b$ bandh). Only foods that are "hot" should be consumed, and "cold" foods should not be consumed, as consuming cold foods could have an influence on the health of the child

[Rekha, Satnami]

'Even if you feel like eating you should not'

[Rupa, Satnami - on deliberate eating-down during breastfeeding]

I of course could eat it (meat) but it should also be digestible to her is it not?

[Kalpana, Satnami - explaining her eating-down meat when breastfeeding]

Amongst us, we give food immediately (to the mother). We give rice, water - ask the mother to drink water 'to her fill' - we give vegetables, chicken, dry fish everything, we give food quickly or else the cold will set in. It is when the mother eats that her breasts fill with milk.

[Akhila Bai, Pardhi]

For the immediate postpartum, all communities prescribe the mothers consumption of foods classified as having heating properties and disallow cooling foods. Furthermore, the Satnami, Yadav and Sahu castes (all except the Pardhi) traditionally restrict food intake of the mother, to keep her 'empty stomach' (khali-pet) while also limiting water consumption. Traditionally, a mother's sole food in the first few days postpartum is the sooth-gur ladoo - a preparation of ginger, jaggery, dry fruits, coconut and spices - considered to be heating and strength building. The mother's body is conceived as 'cold', 'wet' and 'wounded' and restricting food, water and especially rice intake is expected to help it dry, heal and expel residual birth related impurities. The logic is that rice consumption will prevent the body from 'drying'. While not readily classified as 'cold', rice is not considered warming ${ }^{\text {xvii }}$. Traditionally, most women had their first full meal, and resumed rice consumption only at the chatthi, a celebration held 5-6 days postpartum. They maintain however, a deliberate intake of 'less than to a full stomach' (kum kum khana) and gradually progress over 12 months from one regulated daily meal to an intake 'to a full-stomach' (pet-bhar).

In contemporary Nariar, rules are marginally relaxed and most women are allowed hot tea, small portions of wheat roti, and biscuits between 1-2 days postpartum, and rice from 2-3 days. Older women speak disparagingly of the 'weakness' of 
contemporary mothers, unable to endure 5 days without food, although they concede that in light of postpartum exhaustion from food abstinence, the current practice of allowing some food was perhaps better than allowing none. The core ideas around rice-avoidance, eating down and consuming heating foods persist however.

It is noteworthy that although the Pardhi share ideas and practices on postpartum food consumption by humeral 'hot' and 'cold' criteria, they do not encourage postpartum rice-avoidance or eating-down. They view instead postpartum food intake as essential for production of breast milk and for rebuilding maternal strength, and hence, serve the mother a meal soon into the postpartum. This usually comprises of rice and other foods with a view to include nutritious foods such as drumstick or dry fish, which she may eat to 'a full stomach'. Apart from this noteworthy difference in ideas about postpartum maternal dietary intake quantity and timing, all communities, Pardhi, nonPardhi alike, restrict maternal diet to foods classified as 'hot' through much of the child's first year. Mothers are duty-bound to observe consumption of heating foods and to restrict specific foods in the interests of the child's ability to 'digest' breast milk. For instance, mothers restrict consumption of the valued meat, which as a 'hot' food is not proscribed, but is viewed as difficult for infants to digest. Further, mothers must observe absolute abstinence from certain foods - sour foods and a wide range of foods classified as 'cold' over several months. Chhattisgarh's history of high fertility, with 6-8 offspring being usual only a generation ago, indicates that women have repeatedly modified diets for considerable time over their reproductive lives. Table 1 outlines common foods by humeral properties, and Table 2 indicates length of postpartum food avoidance.

Table 1: Common foods classified by 'hot' and 'cold' by humeral properties

\begin{tabular}{|l|l|}
\hline Hot & Cold \\
\hline meat & all sour foods \\
\hline dried fish & raw fish \\
\hline milk & aubergine \\
\hline vadi - dried lentil balls & almost all green leafy vegetables \\
\hline drumstick-munga bhaji and drumstick leaves. & chinchinya bhaji-a leafy vegetable \\
\hline lentils & banana \\
\hline wheat biscuits & yoghurt \\
\hline tea & tomato \\
\hline khari-type of biscuit & cold water \\
\hline roti (wheat based) & lauki - gourd \\
\hline karela & onion \\
\hline egg & \\
\hline
\end{tabular}


Table 2: Length of postpartum food avoidance or abstinence

\begin{tabular}{|c|c|}
\hline rice & $\begin{array}{l}\text { Not readily classified as 'cold' but restricted in the postpartum by all } \\
\text { except the Pardhi. Seen as preventing the mother's body from } \\
\text { drying/healing. Rice is abstained from for } 2-3 \text { days postpartum and eaten- } \\
\text { down for about } 3 \text { weeks or upto } 3 \text { months in case of delivery via a surgical } \\
\text { procedure. The Pardhi do not avoid/abstain from rice. }\end{array}$ \\
\hline $\begin{array}{l}\text { green leafy } \\
\text { vegetables }\end{array}$ & $\begin{array}{l}\text { Strict abstinence from most green leafy vegetables from the early months } \\
\text { postpartum with some restrictions extending for } 1 \text { year (chinchinya bhaji, } \\
\text { karmata bhaji and a range of others). } \\
\text { Spinach (pala bhaji), and red bhaji are allowed (with some hesitation) } \\
\text { between 9-12 months. }\end{array}$ \\
\hline sour foods & Avoided for about 1 year \\
\hline tomato & Avoidance for 3-7 months \\
\hline $\begin{array}{l}\text { aubergine } \\
\text { and yoghurt }\end{array}$ & Abstinence for larger part of 1 year \\
\hline banana & Strict abstinence until 1 year. Viewed to cause the child to develop a cold. \\
\hline cold water & $\begin{array}{l}\text { Cold water avoided for between } 15 \text { days to } 1 \text { month postpartum depending } \\
\text { on the weather (hot water is drunk). Avoided for a longer-duration when } \\
\text { the birth is via caesarean section, and in the winter/rainy seasons. }\end{array}$ \\
\hline
\end{tabular}

Although reproduction is increasingly medicalised and there is, for instance, wide acceptance of the caesarean delivery and tubectomy procedures, it is striking that emic nutrition ideas and practices are further accentuated in an environment where reproduction interacts with surgical procedures. I carry forward the discussion of Kalpana's pregnancy to illustrate.

\section{Encounters with biomedical childbirth}

At the time of delivery, as signs were not good - water broken but no pain the suiyan (traditional birth attendant) recommended that Kalpana be taken to the hospital. Had the onset of labour looked normal, the family would prefer a home birth. Now however, they approached the familiar 'Priya Multi' private hospital where, on November $27^{\text {th }} 2011$, Kalpana gave birth to her daughter. Radhika was a healthy 3-kilogram at birth but was delivered via the muchfeared 'big-operation' or caesarean delivery. I met Kalpana back in Nariar 9 days postpartum. At the hospital she was off food and water for the first 24 hours. Back home, given the 'big-operation', cultural rules on diet were especially fortified, despite the doctor's counsel to 'eat everything' and 'eat to your full'. Compared to a vaginal birth, the big-operation was perceived to inflict greater internal damage and hence entailed extra precaution. 'The doctor will say eat everything, now we would not listen would we? He will "even" tell you to drink cold water'. This blasphemous advice, Kalpana remarked, could only be motivated by the doctor's self-interest to keep patients returning.

At 9 days postpartum, apart from the essential sooth-gur ladoo, Kalpana was consuming a noon rice meal, while skipping the evening meal. She was also 
deliberately eating-down and abstained from all foods classified as 'cold' including green leafy vegetables, select other vegetables, fruits, and sour foods. Meat was allowed, but 'in moderation' (dekh dekh ke). Kalpana would, moreover, drink hot water for longer than the usual norm.

A month later (January 7) Kalpana had lost significant weight from eatingdown and from nursing. She continued the sooth-gur ladoo. Rice was yet consumed only at the noon meal (the evening meal was light, without rice). Nearly two months postpartum (January 23), she had recently begun to include the staple rice in the evening meal. As temperatures were yet cold, she continued to drink hot water. She maintained eating in moderation, 'to a full stomach, but not quite like before'. She would avoid sour foods and foods classified as 'cold' with a view to prevent child illness, for much longer. By late January, when Radhika was about two months old, Kalpana and Harish felt that breast milk was proving inadequate and had begun Radhika on Nestle infant formulae.

The notion that a surgical procedure on the abdomen requires long[er]-term 'eating down' extends beyond childbirth, to other situations of surgical intervention such as the tubectomy. The enhanced and longer-duration post-operative eating down together with food-avoidance is inadequately recognised by health services in Chhattisgarh and is noteworthy to consider for effects on maternal and child health, especially as caesarean deliveries and the tubectomy become routine. Biomedical research has shown a lack of association between maternal dietary intakes or nutritional status and the nutrient quality of breast milk (Quinn et al. 2012). However as Allen (2012) points out, there are important gaps in biomedical evidence in this area. It is assumed with inadequate study, she says, that poor breast milk quality does not play a major causal role in the widespread growth faltering in developing countries over the first year (362). The significant-duration dietary modification, including accentuated eating down, across repeated pregnancies, suggests the need for deeper examination of its health effects. Diet modifications in light of the tubectomy are noteworthy, as the procedure is commonly undertaken when the mother is nursing an older child (who may be between 10 months to 2 years old). While a range of factors influence lactation and this study does not seek to imply biomedical causation, observation suggests that post-operative eating down could, in interaction with other factors, influence maternal nutritional status and lactation, especially when nursing an older child, who depend on greater breast milk volume (breast milk remains a significant nutrient source well into a child's second year). 


\section{When the child can 'crawl and sit'- Infant nutrition in Nariar}

Women in Nariar usually reacted with disbelief on first learning that the author's own infant son, 9-12 months of age during early research contact, was in Raipur at a distance of over 1 hour while the author was in Nariar for the day. Informants often concluded 'you city folk must feed bottle-milk'. Explanations that the child was in fact breast-fed but also consumed solids complementary to breast milk, were received as unfathomable 'how could a child so little eat solids? Our children would not be able to digest them'. As noted, both biomedical as well as emic stances view breast milk as the best form of infant nutrition. In Nariar however, breast milk remains the near exclusive nutrient source for a significantly longer duration than the recommended 6 months. The child is perceived as ready for solids only at the physiological stage when 'he can sit, crawl and attempt to pull himself to standing position', commonly between 9-12 months, when he expresses interest in food and picks it 'on his own'. Consumption of foods apart from breast milk for children up to 9-10 months of age is tokenistic. On a usual day, a 9-10 month old child may consume 1-2 biscuits (similar to the popular brand of biscuits, Parle-G), a piece of fruit or savoury snack and 1-2 tablespoons of rice. This is about $100 \mathrm{kcal}$ from sources other than breast milk (approximately 35 calories from 2 biscuits, 35 calories from 2 tablespoons rice +30 calories from any other food). While recommendations for energy requirement are contested, and depend on child body weight, $100 \mathrm{kcal}$ is about 1/7th of a 9-10 month

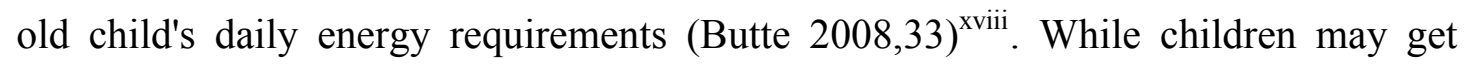
variable nutrition from breast milk, guidelines suggest that daily energy needs from complementary foods for infants from developing countries with 'average' breast milk intake are approximately $200 \mathrm{kcal}$ at 6-8 months, $300 \mathrm{kcal}$ at 9-11 months and $550 \mathrm{kcal}$ at 12-23 months (WHO 2003). By this guideline, children at 9-10 months in Nariar depending on their breast milk intake are possibly short of up to $200 \mathrm{kcal}$ per day. Moreover, few children between 12-23 months consume 550 kcal daily from sources other than breast milk. Table 3 below outlines nutritional status of children in Nariar, for June 2012. The data is extracted from records of a village aanganwadi, and analysed by the author against the international WHO Child Growth Standards. The aanganwadi worker was given a financial incentive by the author to carry out the weight recording, a task mandated by the ICDS. The table represents weight for age data for almost all of Nariar's children in the 0-3 years, barring a few who were out of 
the village or otherwise unavailable. Whilst no statistical tests have been carried out, the aanganwadi data from Nariar suggest that 0-3 Underweight for Age figures compare adversely to averages for rural Chhattisgarh from the third National Family and Health Survey (NFHS-3).

Table 3: Weight for Age for 0-3 year old children in Nariar (June 2012)

\begin{tabular}{|c|c|c|c|}
\hline \multicolumn{3}{|c|}{ Weight for Age - 0-3 years June 2012} & \multirow{2}{*}{$\begin{array}{c}\text { NFHS } 3 \text { (2005-6) } \\
\text { Chhattisgarh (rural) } \\
\text { Percentage } \\
\end{array}$} \\
\hline & \# Observations & Percentage & \\
\hline $\begin{array}{l}\text { UNDERWEIGHT FOR AGE } \\
\text { (weight for age }<-2 \text { SD below } \\
\text { international population norm) }\end{array}$ & 33 & 57.9 & 50.1 \\
\hline $\begin{array}{l}\text { WITHIN NORMAL RANGE } \\
\text { (weight for age }+ \text { or }-2 \text { SD } \\
\text { international population norm) }\end{array}$ & 24 & 42.1 & 49.9 \\
\hline Total & 57 & & \\
\hline
\end{tabular}

\section{Infant feeding: Locus of control}

It is better if the child eats by himself. If we feed, we might feed too much and the child may not be able to digest it'

A child on being actively "fed" [solids other than breast milk] would "poo all the time"

[Rupa, Satnami mother of a ten-month old Nikhil]

How would you like it if someone was to feed you?

[Sumana, Pardhi -to question about the act of feeding one-year-old Tulika]

The statements above on common attitudes towards infant feeding suggest that the child, rather than an adult, is perceived as the best judge of food requirements. While adults offer foods to young children, this is usually when they show particular interest, or if the mother wishes to share a treat such as a biscuit, snack or sweet. Insisting that the infant or young child consume an allocated meal portion is viewed as unnecessary however, and potentially even harmful. Mothers clarify that they do not allocate a 'separate' meal portion. They commonly report moreover that children are healthier when they were eating 'on their own', usually well into their second year. While many in resource poor settings in India and South Asia are known to initiate complementary foods later than biomedical ideals ${ }^{\mathrm{xix}}$, examples from other 
resource poor environments indicate that if health ideas prioritise active infantfeeding, societies may align activities around it. Richards (1939) work on the Bemba, a tribe whose overall diets she describes as inadequate and variable, illustrates a particularly noteworthy contrast.

...The belief that the breasts give comfort rather than nourishment is correlated with the practice of feeding infants with supplementary foods. The Bemba deny entirely that a baby can live even for a few weeks on its mother's milk alone. From the third or fourth week the infant is fed with a thin milk gruel known as 'umusunga'... This umusunga is literally rammed down the baby's throat in spite of its protests.

...it is relentlessly forced down again, pushed with the mother's forefinger or held in the baby's mouth while the food is stroked down his throat, as a European may force a dog to swallow a pill... How can the child get strong if he has nothing but the breast? Parents will say indignantly. They criticize severely European mothers who suckle their babies for six months without additional food...

... [at crawling age] he is allowed and even encouraged to eat everything he can...

(Richards 1939, 69-70)

The dissimilarity between the Bemba and Nariar scenarios is striking, although both diverge from biomedical ideals. Ideas on infant nutrition in Nariar can be summed up as 'breast is best' for as long as may be possible; that the infant and young child's digestion capabilities for foods other than breast milk are limited; and that the infant should determine and control his nutrient intake, suggesting that adults intervene little by way of active feeding.

\section{Concluding reflections}

Pelto and Pelto discuss that the idea of 'systemness' important in anthropological theory - that cultural beliefs and behaviours were holistically related, making changes in health behaviours or acceptance of modern medicine dependent on fundamental shifts in belief systems - was challenged and modified with the worldwide observation of 'pluralistic healthcare practices' (Pelto and Pelto 1997: 150-151). Evidence from Nariar suggests that notwithstanding the widespread acceptance of biomedicine, in reproduction, as well as in treatment of most childhood and adult illness, dietary behaviour as it relates to mothers and infants in the postpartum and early childhood, continues to be shaped by a complex system of ideas on the 
relationship between food and health. Nutrition ideas form perhaps the core elements of a belief system, which while not static, is more resistant to change. However, although practices relating to pregnancy, the postpartum and to child rearing in the early years evidently reflect cultural traditions and ideational formulations, in the context of Nariar, certain caring practices suggest possible adaptations to historical lived experiences of health risks. For instance, the extended reliance on safe breast milk is perhaps shaped by constraints of the health environment. In a setting where public and private health services have been sorely inadequate, and where private healthcare remains expensive and of uncertain quality, the event of child illness is cause for great anxiety. In the words of Sumana Pardhi it puts the family in 'a state of mind where we don't know where to go and what to do, "forcing" us to take a decision'. If local informal medical practitioners cannot assist, the family is compelled to seek care in distress, usually in the private sector, at significant financial costs and at risk of coerced indebtedness. Furthermore, in the case of health-related travel to Raipur, multiple individuals travel together for courage, for collective decision-making and to cope with much-feared eventualities such as having to 'admit' the child at a health facility. This disrupts livelihoods, and can be financially or otherwise catastrophic. The Pardhi, and other communities are then terrified about a young child becoming ill, or being set-back for instance by diarrhoea, and this anxiety expressly shapes their extended reliance on breast milk as a nutrient source. Levine (1988) has proposed that differences in childrearing patterns evolved in response to environmental risks threatening child survival and self-maintenance. Commencing complementary foods is a delicate process even when environmental health and food quality is good, since a child's digestive system learns to cope with solids only gradually ${ }^{\mathrm{xx}}$. Thinking aloud on a question about complementary foods, Sumana Pardhi, whose one year old daughter Tulika was two months older than the authors son, and virtually exclusively on breast milk at the time, remarked 'it may be that your (the authors) child is able to eat solid foods since he was exposed to "inside air" (andar ki hawa) while for our Pardhi children it is "unthinkable" since they are exposed to "outside air" (bahar ki hawa) and unable to deal with solid foods so young'. The mention of hawa or 'air' is an idiomatic reference to the entire environment, and Sumana was comparing the overall health vulnerabilities to which the respective children were exposed. In the region of Nariar, the historical difficulty of dealing with child illness, such as gastro-intestinal conditions or diarrhoea appears 
to contribute to the practice of extended reliance on the safe breast milk. In this sense, health behaviours reflect perhaps some adaptive strategies. Moreover, some changes in caring practices are attributed to the now easier access to biomedical healthcare. A Satnami grandmother remarked for instance that the formerly common practice of placing a heated iron sickle into hot water that was for postpartum consumption by the mother (to promote health and prevent iron deficiency) was now unnecessary as doctors were more readily accessible.

Interpreted in light of current biomedical criteria, in relation to gestational nutrition, health beliefs concerning food avoidances appear to have few consequences, although maternal micronutrient pill supplements are avoided from fear of their creating a 'toolarge' foetus that may make for a difficult delivery. While gestational food restrictions are negligible, nutrient rich foods have a clear income-dependence, and costs limit diet quality. Although costs are a barrier, there is, in Nariar, some scope to reorder household resources towards nutrition. In the case of Kalpana, and for some other women in Nariar, while significant resources are dedicated to biomedicine and private healthcare, gestational nutrition is less prioritised. In the postpartum, food restrictions bear on diet quality, maternal nutritional status and potentially on child nutritional status. In an environment where overall diets are poor and fertility has been high, these long-term, and repeated - with each pregnancy - dietary restrictions are likely to have negative implications for maternal nutrition, since they do not appear to be compensated by noticeable change in work patterns or alternate diets.

Given that nutrition remains largely conditioned by traditional and widely shared cultural beliefs alongside the widespread acceptance of biomedicine, the extended 'eating down' post a surgical procedure such as a caesarean delivery, or the tubectomy is particularly noteworthy. Food intake quantities are reduced for an extended time, over a period of 2-3 months. This can plausibly affect breast milk production, and its adequacy for a growing infant, or toddler. This subject merits deeper examination from additional research. An infant's near exclusive dependence on breast milk through the first year and into the second year of life is by biomedical standards inadequate to meet the growing child's nutrient demands, although biomedical infant feeding ideals are challenged by current day baby-led weaning movements in western countries. While cultural formulations on digestion, and where 
locus of control in infant-feeding should lie shapes diets, childrearing practice also reflects, perhaps, the historical lived experience of health risks. 


\section{References}

Allen, L. H. 2012. "B Vitamins in Breast Milk: Relative Importance of Maternal Status and Intake, and Effects on Infant Status and Function." Advances in Nutrition: An International Review Journal 3 (3): 362-69.

Bhutta, Z.A., Das, J.K., Rizvi, A., Gaffey, M.F., Walker, N., Horton, S., Webb, P., Lartey, A., Black, R.E., Group, T.L.N.I.R. and Maternal and Child Nutrition Study Group, 2013. "Evidence-based interventions for improvement of maternal and child nutrition: what can be done and at what cost?" The Lancet,382(9890),pp.452-477.

Boseley, Sarah. 2008. "Robert Black: Time to Tackle Undernutrition." The Lancet. doi:10.1016/S0140-6736(08)60123-3.

Brems, S, and A Berg. 1988. "“Eating Down" during Pregnancy": Unpublished Discussion Paper. The World Bank.

Butte, N.F. 2008. "Energy Requirements of Infants, Children and Adolescents" in Pediatric Nutrition In Practice

Census of India, 2011

Chastre, C., Duffield, A., Kindness, H., Lejeune, S. \& Taylor, A. 2007. "The Minimum Cost of a Healthy Diet: findings from piloting a new methodology in four study locations". Save the Children UK.

Christian, P., Bunjun Srihari, S., Thorne-Lyman, A., Khatry, S.K., LeClerq, S.C. and Ram Shrestha, S., 2006. Eating down in pregnancy: exploring food-related beliefs and practices of pregnancy in rural Nepal. Ecology of food and nutrition, 45(4), pp.253-278.

De-Regil, Luz Maria, Ana C. Fernández-Gaxiola, Therese Dowswell, and Juan Pablo Peña-Rosas. 2010. "Effects and safety of periconceptional folate supplementation for preventing birth defects." The Cochrane Library.

Devakumar, Delan, Shiva Shankar Chaube, Jonathan C K Wells, Naomi M Saville, Jon G Ayres, Dharma S Manandhar, Anthony Costello, and David Osrin. 2014. "Effect of Antenatal Multiple Micronutrient Supplementation on Anthropometry and Blood Pressure in Mid-Childhood in Nepal: Follow-up of a Double-Blind Randomised Controlled Trial." The Lancet. Global Health 2 (11): e654-63.

Dibley Michael J and Senarath Upul eds. 2012. Maternal and Child Nutrition, Vol.8,Supplement1,January.

Engle, Patrice. 2002. "Infant Feeding Styles: Barriers and Opportunities for Good Nutrition in India." Nutrition Reviews 60 (5 Pt 2): S109-14. 
Fall, Caroline, David Fisher, Clive Osmond, Barrie M. Margetts, Pierre Adou, Victor Aguayo, Lindsay Allen, et al. 2009. "Multiple Micronutrient Supplementation during Pregnancy in Low-Income Countries: A Meta-Analysis of Effects on Birth Size and Length of Gestation." Food and Nutrition Bulletin 30.

Ferro-Luzzi, GE. 1980. "Food Avoidances of Pregnant Women in Tamilnad." Food, Ecology and Culture: Readings in the Anthropology of Dietary Practices, 101-8.

Fewtrell, Mary, David C Wilson, Ian Booth, and Alan Lucas. 2011. "Six Months of Exclusive Breast Feeding: How Good Is the Evidence?" BMJ (Clinical Research Ed.) 342: c5955. doi:10.1136/bmj.c5955.

Good, Byron J. 1993. Medicine, rationality and experience: an anthropological perspective. Cambridge University Press,

Huffman, S L, E R Zehner, and C Victora. 2001. "Can Improvements in BreastFeeding Practices Reduce Neonatal Mortality in Developing Countries?" Midwifery 17 (2): 80-92. doi:10.1054/midw.2001.0253.

Jeffery, Patricia, Roger Jeffery, and Andrew Lyon. 1989. Labour Pains and Labour Power: Women and Childbearing in India. Zed Books.

Kramer, Michael S, and Ritsuko Kakuma. 2012. "Optimal Duration of Exclusive Breastfeeding." Cochrane Database of Systematic Reviews (Online) 8 (4): CD003517. doi:10.1002/14651858.CD003517.pub2.

LeVine, Robert A. 1988. "Human parental care: Universal goals, cultural strategies, individual behavior." New Directions for Child and Adolescent Development, no. 40 (1988): 3-12.

Lock, Margaret, and Nancy Scheper-Hughes. "A critical-interpretive approach in medical anthropology: Rituals and routines of discipline and dissent." Medical anthropology: Contemporary theory and method 3 (1990): 47-73.

Messer, Ellen. 1989. "Small but Healthy? Some Cultural Considerations." Human Organization, no. 48: 39-52.

Nag, Moni. 1994. "Beliefs and Practices about Food during Pregnancy: Implications for Maternal Nutrition." Economic and Political Weekly 29 (37): 2427-38. doi:10.2307/4401755.

NFHS-3. 2005-06. Third National Family Health Survey.

Nichter, M. 1983. "The Ethnophysiology and Folk Dietetics of Pregnancy: A Case Study from South India." Human Organization 42 (3): 235-46. doi:10.4324/9780203393390.

Placek, C.D. and Hagen, E.H., 2015. "Fetal Protection". Human Nature, 26(3), pp.255-276. 
Pelto, Gretel H., Emily Levitt, and Lucy Thairu. 2003. "Improving Feeding Practices: Current Patterns, Common Constraints, and the Design of Interventions." Food and Nutrition Bulletin 24 (1): 45-82.

Pelto, Pertti J, and Gretel H Pelto. 1997. "Studying Knowledge, Culture, and Behavior in Applied Medical Anthropology." Medical Anthropology Quarterly 11 (2). Wiley Online Library: 147-63.

Quinn, E.A., Largado, F.E., Power, M. and Kuzawa, C.W., 2012. Predictors of breast milk macronutrient composition in Filipino mothers. American Journal of Human Biology, 24(4), pp.533-540.

Rapley Gill, 2016. "Starting solid foods: does the feeding method matter?" Early Child Development and Care, DOI: 10.1080/03004430.2016.1250080

Reilly, John J., and Jonathan CK Wells. 2005. "Duration of exclusive breast-feeding: introduction of complementary feeding may be necessary before 6 months of age." British Journal of Nutrition 94, no. 06: 869-872.

Richards, Audrey.1939. "Land, Labour and Diet: An Economic Study of the Bemba Tribe."

Ronsmans, Carine, David J. Fisher, Clive Osmond, Barrie M. Margetts, Caroline HD Fall, and Maternal Micronutrient Supplementation Study Group. 2009.

"Multiple Micronutrient Supplementation during Pregnancy in Low-Income Countries: A Meta-Analysis of Effects on Stillbirths and on Early and Late Neonatal Mortality."' Food and Nutrition Bulletin 30 (no. 4): S547-55.

Singer, Merrill. "The coming of age of critical medical anthropology." Social Science \& Medicine 28, no. 11 (1989): 1193-1203.

Townsend, Ellen, and Nicola J. Pitchford. "Baby knows best? The impact of weaning style on food preferences and body mass index in early childhood in a casecontrolled sample." BMJ open 2, no. 1 (2012): e000298.

Unicef, 2013. Improving child nutrition: the achievable imperative for global progress. New York

Van Hollen, Cecilia, 2003. Birth on the threshold: childbirth and modernity in south India. Univ of California Press, 2003.

WHO. 2002. "Report of the Expert Consultation on the Optimal Duration of Exclusive Breastfeeding." World Health Organization.

World Health Organization. 2003. "Complementary Feeding: Report of the Global Consultation, and Summary of Guiding Principles for Complementary Feeding of the Breastfed Child."

Wright, Charlotte M., Kirsty Cameron, Maria Tsiaka, and Kathryn N. Parkinson. 2011. "Is baby-led weaning feasible? When do babies first reach out for and eat 
finger foods?" Maternal and child nutrition 7, no. 1: 27-33.

\begin{abstract}
' See for instance Pelto and Pelto (1997); Good (1993).
ii They contend that India's flagship Integrated Child Development Services is hijacked to become a 'feeding' programme, and that it should emphasise instead health education. Alternative positions view key nutrition impediments as economic, stemming from deprivation and food insecurity (Chastre et al.
\end{abstract} 2007). India's Right to Food Campaign is also forceful in emphasizing food provisioning. Unequal gender relations and the poor health environment are further viewed as key barriers.

iii Based on new evidence that extending breastfeeding met nutrient needs and additionally offered greater protection against gastrointestinal infections.

${ }^{\text {iv }}$ The author has a background in policy-engaged health research.

${ }^{v}$ Most intensive engagement was between November 2011-May 2012.

vi Under the Criminal Tribes Act (1924). As the act was repealed in 1952 the tribes were 'de-notified'.

vii The research site was identified in September 2010 and scoping fieldwork was carried out in November 2010. Research was resumed from September 2011. The author has returned to Nariar every year since.

viii Nag's review finds that the overall pattern is to avoid hot foods in pregnancy, although he notes in summary that for some communities, food avoidance by 'hot' or 'cold' criteria are believed to vary in different stages of pregnancy and by individual physical constitution (Nag 1994, 2427).

ix The climate from the fifth month of Rekha's pregnancy was hot, and the temperatures in the months of April, May and June can be severe (touching 45 degrees Celsius).

${ }^{x}$ Literature on the nature/extent of eating down is scant. Recent research from Nepal indicates that eating down with a view to prevent difficult deliveries was uncommon (Christian et al. 2006).

${ }^{x i}$ Mirroring conclusions of other anthropological work on perceptions of baby size (Messer 1989).

${ }^{x i i}$ Between 2010-12, 40\% births in Nariar were institutional while 60\% were home-based $(\mathrm{N}=40)$.

xiii Trials have shown small birth weight increases from antenatal multiple micronutrient supplementation (Bhutta et al. 2013; Fall et al. 2009), and their wider programmatic incorporation is recommended (Bhutta et. al 2013). Existing biomedical evidence is small however. It is argued that longer-term impacts of micronutrient supplementation are unclear and effects not unidirectional (Devakumar et al. 2014). A meta-analysis of trials on antenatal multi-micronutrient pill supplementation found supplementation linked with increased birth weights but with no effects on stillbirths or early neonatal mortality. In fact, on excluding results of one study the meta-analysis showed an increase in neonatal mortality despite an increase in birth weights (Ronsmans et al. 2009). Biomedical evidence is more conclusive on benefits of iron supplementation (for prevention of anaemia) and periconceptual folic acid supplementation (prevention of neural tube defects). See Bhutta et al (2013) and De-Regil et al. (2010).

xiv This is reflected in Chhattisgarh's near neutral adult sex ratio (991:1000) and feminine child sex ratio (964:100). Census of India (2011).

${ }^{\mathrm{x} v}$ Colostrum is frequently viewed as impure and sugar water, honey or animal milk are common first foods (Jeffery et al. 1989).

xvi Anthropological work in other parts of India also shows that postpartum diet is significantly modified (see for instance Jeffery et al. 1989; Van Hollen 2003)

xvii Informants did not articulate clear reasons why rice consumption may prevent the mothers body from healing/drying. Van Hollen (2003) suggests that the viscous character of cooked rice might be a factor in Tamil Nadu. 
xviii Energy requirements for children (8-10 months): 702-731 kcal per day for boys and 652-676 kcal per day for girls (Butte 2008,33).

${ }^{x i x}$ See for instance Engles (2002) and papers in Dibley and Senarath, eds. (2012).

${ }^{x x}$ See for instance (Pelto, Levitt, and Thairu 2003). 